\title{
Ethnobotanical survey of medicinal dietary plants used by the Naxi People in Lijiang Area, Northwest Yunnan, China
}

\author{
Lingling Zhang ${ }^{1,2}$, Yu Zhang ${ }^{1}$, Shengji Pei ${ }^{1}$, Yanfei Geng ${ }^{1,3}$, Chen Wang ${ }^{1}$ and Wang Yuhua ${ }^{1 *}$
}

\begin{abstract}
Background: Food and herbal medicinal therapy is an important aspect of Chinese traditional culture and traditional Chinese medicine. The Naxi are indigenous residents of the Ancient Tea Horse Road, and the medicine of the Naxi integrates traditional Chinese, Tibetan, and Shamanic medicinal systems, however, little is known about the medicinal dietary plants used by the Naxi people, or their ethnobotanical knowledge. This is the first study to document the plant species used as medicinal dietary plants by the Naxi of the Lijiang area.

Methods: Ethnobotancial surveys were conducted with 89 informants (35 key informants) from 2012 to 2013. Three different Naxi villages were selected as the study sites. Literature research, participatory investigation, key informant interviews, and group discussions were conducted to document medicinal dietary plants and the parts used, habitat, preparation methods, and function of these plants. The fidelity level (FL) was used to determine the acceptance of these medicinal dietary plants. Voucher specimens were collected for taxonomic identification.

Results: Surveys at the study sites found that 41 ethnotaxa corresponded to 55 botanical taxa (species, varieties, or subspecies) belonging to 24 families and 41 genera. Overall, $60 \%$ of documented plants belonged to seven botanical families. The most common families were Compositae (16.4 \%) and Rosaceae (10.9\%). Roots (34.1\%) were the most common part used. Wild-gathered (68.3\%), semi-domesticated (17.1\%), and cultivated (14.6\%) were the most common habitats of medicinal dietary plants. Stewing plants with meat was the most common preparation and consumption method. The plants were used to treat 21 major health conditions; alleviating fatigue (42.8\%) was the most common. The maximum FL of 100 was found for $68.3 \%$ of the medicinal dietary plants

Conclusions: The medicinal dietary plants used by the Naxi people are diverse and are used to treat a wide spectrum of body disorders. Further studies focusing on safety, detoxification, and nutritional value of the plants should be conducted to allow them to be used to improve health and prevent diseases in modern society.
\end{abstract}

Keywords: Medicinal dietary plant, Traditional Chinese medicine, Ethnobotany, Naxi, Lijiang

\section{Background}

There is much overlap between medicine and food [1-5], and dietary products can simultaneously be a food and a medicine [2-4, 6-11]. In fact, many plants in local food cultures are inseparable from traditional therapeutic systems $[8,12-15]$. China has a long cultural history of homologous medicine and food, and the thought of "food as medicine" has existed in China since ancient times [16,

\footnotetext{
* Correspondence: Wangyuhua@mail.kib.ac.cn

'Kunming Institute of Botany, Chinese Academy of Sciences, Kunming 650201, China

Full list of author information is available at the end of the article
}

17]. Therefore, food therapy is an important characteristic of Chinese culture and traditional Chinese medicine (TCM). The concept of food therapy was proposed 20003000 years ago in the Inner Canon of Huangdi [18]. In the Tang Dynasty, food was used to treat diseases and the famous medical expert Sun Simiao proposed that "the healer must know the causes of the disease and the disorder of the body, then first treat with food, if it does not work, then medicine could be adopted" [19]. Food therapy as a part of TCM is based on the Chinese philosophy of Yin -Yang and the Five Elements (metal, wood, water, fire and earth) [20]. Food therapy uses holistic principles as its 
base, and highly emphasizes harmony within the universe $[20,21]$, while preventing disease by enhancing the condition of the body.

A medicinal diet includes using medicines in the diet or functional foods used as medicines, based on the current health-status of an individual, as well as the overall epidemiological situation of a population [19, 21]. Because the population is aging and the number of people who are sub-healthy and living with chronic diseases is increasing, the Chinese medicinal diet has received considerable attention. In the United States, Europe, and Australia, the "non-nutritive" health roles of diet are receiving increasing attention within the areas of functional foods, nutraceuticals, and phytonutrients $[15$, 22-26]. Since 1985, more than ten food therapy books per year have been published in China [27]. However, study of the medicinal diets used by indigenous communities in China has been mostly neglected.

TCM has spread to Lijiang and was adopted by the Naxi people [28]. The population of the Naxi people in China is about 324,679 and mainly they inhabits the Yulong Naxi nationality Autonomous County in the Lijiang area [29]. The Naxi are a Burmo-Naxi-Lolo sociolinguistic sub-group of the Tibeto-Burman group within the Sino-Tibetan family [30]. The Naxi population was formed during the southward migration of the ancient Qiang people during the Qin Dynasty (221-206 $\mathrm{BC}$ ), who had originally inhabited the Hehuang area of Northwest China [30]. The Naxi are indigenous residents of the Ancient Tea Horse Road, a trade link documented since the Tang dynasty (618-907 CE) which lasted until the 1960s, and stretched across Yunnan, Sichuan and Tibetan provinces [31]. The road promoted exchanges in culture, religion and ethnic migration, resembling the Silk Road [32]. Given this history, the medicine of the Naxi integrates traditional Chinese, Tibetan, and Shamanic medicinal systems [28]. Prior research indicates that the Naxi culture promotes diet therapy, and documentation of many of their traditional medicines and diet remedies exists through the world's only remaining pictographic writing system [33]. Despite the renewed interest in medicinal diets by scientists, consumers, and industry, not much is known about the medicinal dietary plants used by the Naxi, or their associated ethnobotanical knowledge. This is the first study to focus on the medicinal dietary plants of the Naxi People and their associated knowledge. The plant materials, parts used, habitats, and medicinal dietary uses are recorded and the fidelity of the medicinal dietary plants is assessed.

\section{Methods}

Study site

The study was conducted in the Yulong Naxi Nationality Autonomous County in Lijiang Area in Northwest
Yunnan Province, China. Northwest Yunnan is located in the Three Parallel Rivers region, and Lijiang is listed as a World Natural and Cultural Heritage Site by UNESCO. The region's exceptional altitudinal range, topography, and climatic variability have fostered centers of plant species endemism [34-36]. Northwest Yunnan harbors over 3500 endemic plant species, many of which are used by local communities including the Naxi [34, 35, 37]. Three typical Naxi villages (Wenhai, Ludian, and Shihong) were selected as study sites. These villages represent particular landforms in the Northwest Yunnan plateau, and have different positions in the Naxi culture (Fig. 1).

Wenhai village is a typical wet plateau basin located directly on the western foot of the first peak of the Yulong Snow Mountain. The location is $26^{\circ} 59^{\prime} 16.37^{\prime \prime} \mathrm{E}$, $100^{\circ} 10^{\prime} 6.23^{\prime \prime} \mathrm{N}$ and the altitude is between 3109 and $3380 \mathrm{~m}$. Weihai village is an ancient village on the Ancient Tea Horse Road leading to Tibet [32]. Ludian village is a typical dry plateau basin located at the center of the Northwest Yunnan plateau. The location is $103^{\circ}$ $19^{\prime} 12^{\prime \prime} \mathrm{E}, 27^{\circ} 7^{\prime} 48^{\prime \prime} \mathrm{N}$ and the altitude is between 2400 and $2800 \mathrm{~m}$. Ludian village is the last stop of the "Soul Sending Way", which is the transfer road of the Naxi [30]. Shihong village is a typical mountain village located on the southwestern most peak, "Ninety-nine Longtan", of the Laojun Mountain. The location is $26^{\circ} 41^{\prime} 24^{\prime \prime} \mathrm{E}, 99^{\circ}$ $53^{\prime} 49^{\prime \prime} \mathrm{N}$, and the altitude is between 3500 and $3600 \mathrm{~m}$. The village was the first settlement in the surrounding area [38], and both the traditional culture and natural environment are well preserved.

\section{Data collection}

The data were collected from 2012 to 2013, and at least one half of one month of the fieldwork was conducted in each season every year. The methods we adopted included literature research, participatory investigation, key informant interviews, and group discussions [39]. Eighty-nine informants ( 49 men and 40 women) were interviewed. Informant ages ranged from 19 to 85 years old, and those aged above 60 were key informants. The interviews were carried out in standard Mandarin Chinese given that most of the population is bilingual and has attended a Chinese language school. We recorded the local Chinese language names as well as local Naxi names.

Our study began with a literature search, which not only helped identify proper study sites, but also helped us understand flora of Northwest Yunnan and collect the ethnobotanical data of the Naxi. The first step of the fieldwork was participatory investigation, and the main task was to search for medicinal dietary plants with the key informants to perform a quick inventory, collect voucher specimens, record habitats, and take photos. The preparation and consumption procedures were witnessed 


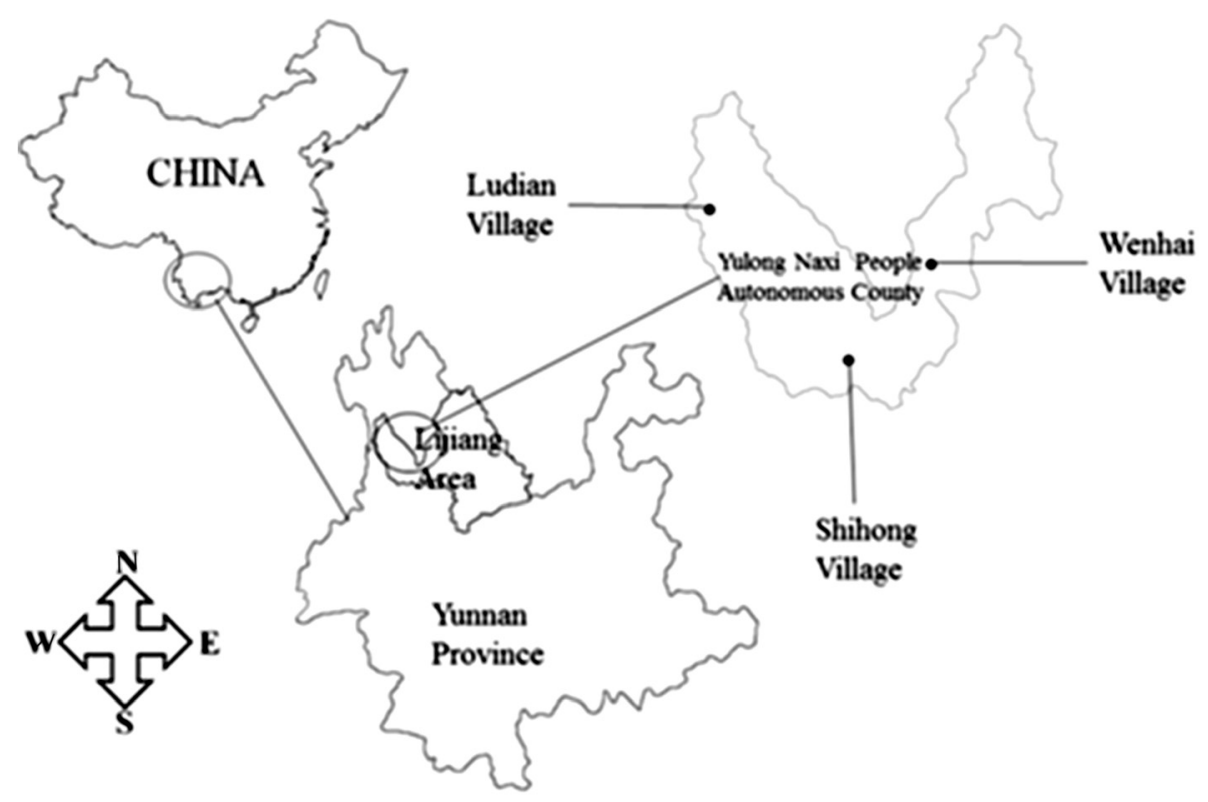

Fig. 1 Location map of study sites

and recorded in the homes of the villagers. After that, key informant interviews were performed. The plant specimens collected in the participatory investigation were used for reference during the key informant interviews. In the key informant interviews, detailed information about each plant, such as the local Chinese and Naxi names, habitat, edible parts, preparation, consumption, and medicinal dietary function, were documented. During group discussions, the information garnered in the first two stages was discussed by a group of informants to ensure accuracy.

\section{Fidelity level}

Fidelity level (FL) was used to assess the acceptance of each medicinal dietary plant at the ethnotaxic level. The formula used was $\mathrm{FL}=\mathrm{Np} / \mathrm{N} \times 100$ [40-42], where $\mathrm{Np}$ is the number of informants stating the use of the plant as a medicinal dietary plant and $\mathrm{N}$ is the total number of informants citing the plant as edible or for medicinal use. As medicinal dietary plants are edible plants can be used as medicine (for example Allium tuberosum, a common vegetable, can be used to calm nerves) or medicinal plants can be consumed with food (for example Aconitum stapfianum is consumed by stewing with meat in winter for its anti-rheumatic benefits), we define $\mathrm{N}$ as the total number of informants citing the plant for edible or medicinal use. The values of FL range from 0 to 100 , and increasing values of FL for a plant indicate its greater acceptance as a medicinal dietary plant.

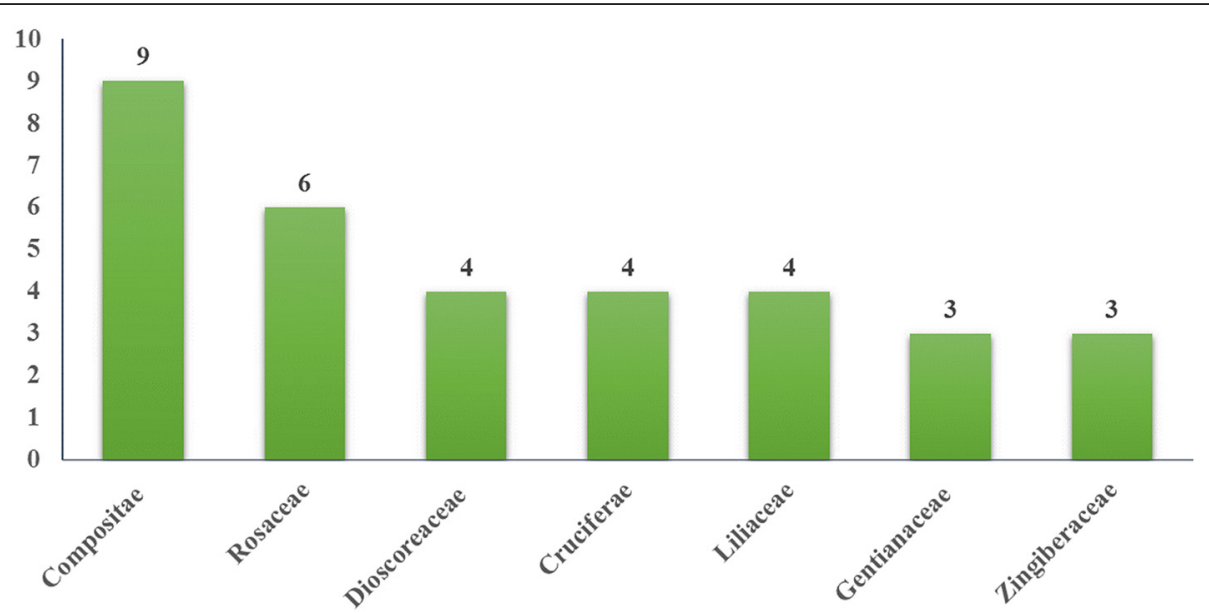

Fig. 2 Most quoted plant families by number of species included 
Table 1 Inventory of medicinal dietary plants used by the Naxi in Lijiang area, Northwest Yunnan, China (Ranked alphabetically, Ethnotaxically organized)

\begin{tabular}{|c|c|c|c|c|c|c|c|c|}
\hline Local name & Family & Scientific name of original plant & Medicinal dietary function & Diet type & Preparation & Part used & Habitat & Voucher specimen code \\
\hline Zhuzishen & Campanulaceae & $\begin{array}{l}\text { Codonopsis convolvulacea } \\
\text { subsp. forrestii (Diels) D. Y. } \\
\text { Hong ex L. M. Ma }\end{array}$ & Treat eye disease & $\begin{array}{l}\text { Medicinal } \\
\text { diet }\end{array}$ & $\begin{array}{l}\text { Stewed with meat; } \\
\text { steamed with egg }\end{array}$ & Root & Wild-gathered & ZLL-0005 \\
\hline Shanyao & Dioscoreaceae & $\begin{array}{l}\text { Dioscorea deltoidea Wall. } \\
\text { ex Griseb.; Dioscorea delavayi } \\
\text { Franch.; Dioscorea hemsleyi } \\
\text { Prain ex Burkill; Dioscorea sp. }\end{array}$ & Alleviate fatigue, Tonifying & $\begin{array}{l}\text { Vegetable, } \\
\text { Medicinal } \\
\text { diet }\end{array}$ & Stewed with meat & Root & Semi-domesticated & $\begin{array}{l}Z Y-0021, Z Y-0022, \\
Z Y-0023, Z Y-0024\end{array}$ \\
\hline Yekuai & Malvaceae & Malva verticillata $\mathrm{L}$. & Postpartum blood stasis & $\begin{array}{l}\text { Medicinal } \\
\text { diet }\end{array}$ & Soup made with egg & Root & Wild-gathered & ZLL-0001 \\
\hline Xuelianhua & Compositae & Saussurea leucoma Diels & Alleviate fatigue, Tonifying & $\begin{array}{l}\text { Medicinal } \\
\text { diet }\end{array}$ & Soaked in boiling water & $\begin{array}{l}\text { Whole } \\
\text { plant }\end{array}$ & Wild-gathered & ZLL-0010 \\
\hline Xuecha & Icmadophilaceae & $\begin{array}{l}\text { Thamnolia vermicularis (Sw.) } \\
\text { Ach.ex Schae; Thamnolia } \\
\text { subuliformis (Ehrh.) W. L. Culb }\end{array}$ & $\begin{array}{l}\text { Treat cold, Clean away heat, } \\
\text { detoxification }\end{array}$ & $\begin{array}{l}\text { Generation } \\
\text { tea }\end{array}$ & Soaked in boiling water & $\begin{array}{l}\text { Whole } \\
\text { plant }\end{array}$ & Wild-gathered & ZLL-0079, ZLL-0080 \\
\hline Xiaohongshen & Rubiaceae & Galium elegans Wall. ex Roxb. & Alleviate backache,bruises & $\begin{array}{l}\text { Medicinal } \\
\text { diet }\end{array}$ & Stewed with meat & Root & Wild-gathered & ZY-0035 \\
\hline Xiangyashen & Zingiberaceae & $\begin{array}{l}\text { Roscoea tibetica Batalin; } \\
\text { Roscoea yunnanensis Loes.; } \\
\text { Roscoea cautleoides Gagnep. }\end{array}$ & Kidney deficiency & $\begin{array}{l}\text { Medicinal } \\
\text { diet }\end{array}$ & Stewed with meat & Root & Wild-gathered & $\begin{array}{l}Z Y-0121, Z Y-0122, \\
Z Y-0123\end{array}$ \\
\hline Xiangru & Labiatae & Origanum vulgare $\mathrm{L}$. & Treat cold & Spices & Boil water & $\begin{array}{l}\text { Aerial } \\
\text { part }\end{array}$ & Wild-gathered & GYF-0061 \\
\hline Wuweizi & Magnoliaceae & $\begin{array}{l}\text { Schisandra chinensis (Turcz.) } \\
\text { Baill. }\end{array}$ & $\begin{array}{l}\text { Alleviate fatigue,treat } \\
\text { insomnia }\end{array}$ & $\begin{array}{l}\text { Fruit, } \\
\text { medicinal } \\
\text { diet }\end{array}$ & Infused with alcohol & Fruit & Wild-gathered & ZLL-0027 \\
\hline Tiaoshen & Compositae & $\begin{array}{l}\text { Stebbinsia umbrella (Franch.) } \\
\text { Lipsch. }\end{array}$ & Alleviate fatigue, Tonifying & $\begin{array}{l}\text { Medicinal } \\
\text { diet }\end{array}$ & Stewed with meat & Root & Wild-gathered & ZLL-0107 \\
\hline Songhuafen & Pinaceae & Pinus armandii Franch. & Moistening lung, Anti-tussive & $\begin{array}{l}\text { Medicinal } \\
\text { diet }\end{array}$ & $\begin{array}{l}\text { Mixed with honey or } \\
\text { brown sugar }\end{array}$ & Pollen & Wild-gathered & ZLL-0060 \\
\hline Songzi & Pinaceae & Pinus yunnanensis Franch. & Moistening lung, Anti-tussive & Nut & Dried & Kernel & Wild-gathered & ZY-0074 \\
\hline Songluo & Parmeliaceae & Usnea longissina Ach. & Moistening lung, Anti-tussive & $\begin{array}{l}\text { Generation } \\
\text { tea }\end{array}$ & Soaked in boiling water & $\begin{array}{l}\text { Whole } \\
\text { plant }\end{array}$ & Wild-gathered & GYF-0082 \\
\hline Songjisheng & Loranthaceae & $\begin{array}{l}\text { Arceuthobium pini Hawksworth } \\
\text { et Wiens }\end{array}$ & Treat insomnia & $\begin{array}{l}\text { Generation } \\
\text { tea }\end{array}$ & Soaked in boiling water & Leaf & Wild-gathered & ZLL-0105 \\
\hline Shanzha & Rosaceae & $\begin{array}{l}\text { Crataegus scabrifolia (Franch.) } \\
\text { Rehd.; } \\
\text { Crataegus chungtienensis } \\
\text { W. W. Smith }\end{array}$ & Appetizing,diuresis & $\begin{array}{l}\text { Fruit, } \\
\text { Candied fruit }\end{array}$ & $\begin{array}{l}\text { Soaked in boiling water, } \\
\text { mixed with honey }\end{array}$ & Fruit & Semi-domesticated & ZLL-0016, ZLL-0017 \\
\hline Shanjinzi & Rosaceae & Malus rockii Rehd. & Appetizing,diuresis & $\begin{array}{l}\text { Fruit, } \\
\text { Candied fruit }\end{array}$ & $\begin{array}{l}\text { Soaked in boiling water, } \\
\text { mixed with honey }\end{array}$ & Fruit & Semi-domesticated & ZLL-0132 \\
\hline Qinciguo & Rosaceae & Prinsepia utilis Royle & $\begin{array}{l}\text { Postpartum weakness, } \\
\text { Tonifying, }\end{array}$ & Oil & Extracted oil & Kernel & Semi-domesticated & ZLL-0075 \\
\hline
\end{tabular}


Table 1 Inventory of medicinal dietary plants used by the Naxi in Lijiang area, Northwest Yunnan, China (Ranked alphabetically, Ethnotaxically organized) (Continued)

\begin{tabular}{|c|c|c|c|c|c|c|c|c|}
\hline Pugong Ying & Compositae & $\begin{array}{l}\text { Taraxacum mongolicum Hand.- } \\
\text { Mazz. }\end{array}$ & $\begin{array}{l}\text { Clean away heat, } \\
\text { detoxification }\end{array}$ & Vegetable & Made into soup & $\begin{array}{l}\text { Aerial } \\
\text { part }\end{array}$ & Wild-gathered & ZY-0002 \\
\hline Niubang & Compositae & Arctium lappa L. & Alleviate fatigue, Tonifying & $\begin{array}{l}\text { Medicinal } \\
\text { diet }\end{array}$ & Stewed with meat & Root & Wild-gathered & ZY-0007 \\
\hline Mugua & Rosaceae & $\begin{array}{l}\text { Chaenomeles speciosa (Sweet) } \\
\text { Nakai }\end{array}$ & Anti-rheumatism & $\begin{array}{l}\text { Fruit, } \\
\text { seasoning }\end{array}$ & Stewed with fish & Fruit & Wild-gathered & ZLL-0013 \\
\hline Muer & Auriculariaceae & $\begin{array}{l}\text { Auricularia auricula (L. ex Hook.) } \\
\text { Underw }\end{array}$ & Gut purge & Vegetable & Cold dish & $\begin{array}{l}\text { Whole } \\
\text { plant }\end{array}$ & Wild-gathered & ZLL-0028 \\
\hline Mianshen & Labiatae & Eriophyton wallichii Benth. & Alleviate fatigue, Tonifying & $\begin{array}{l}\text { Medicinal } \\
\text { diet }\end{array}$ & Stewed with meat & Root & Wild-gathered & ZLL-0065 \\
\hline Manjing & Cruciferae & Brassica rapa L. & Appetizing & $\begin{array}{l}\text { Grain, } \\
\text { vegetable }\end{array}$ & Raw, boiled & Root & Domesticated & ZLL-0045 \\
\hline Luobo & Cruciferae & Raphanus sativus L. & Appetizing & Vegetable & Raw, boiled & Root & Domesticated & ZLL-0069 \\
\hline Longdancao & Gentianaceae & $\begin{array}{l}\text { Gentiana rigescens Franch. ex } \\
\text { Hemsl.; Gentiana szechenyii } \\
\text { Kanitz; Gentiana cephalantha } \\
\text { Franch. ex Hemsl. }\end{array}$ & Kidney deficiency & Ferment & Boiled in water & $\begin{array}{l}\text { Aerial } \\
\text { part }\end{array}$ & Wild-gathered & $\begin{array}{l}\text { ZY-0094, ZY-0095, } \\
\text { ZY-0096 }\end{array}$ \\
\hline Juehuashen & Compositae & $\begin{array}{l}\text { Hippolytia delavayi (Franch. } \\
\text { ex W. W. Smith) Shih }\end{array}$ & $\begin{array}{l}\text { Alleviate fatigue, Tonifying, } \\
\text { moistening lung, Anti-tussive }\end{array}$ & $\begin{array}{l}\text { Medicinal } \\
\text { diet }\end{array}$ & Stewed with meat & Root & Wild-gathered & ZY-0039 \\
\hline Jiucai & Liliaceae & $\begin{array}{l}\text { Allium tuberosum Rottl. ex } \\
\text { Spreng. }\end{array}$ & Calm nerves & Vegetable & Cooked with goat liver & Leaf & Domesticated & ZLL-0032 \\
\hline Jicai & Cruciferae & $\begin{array}{l}\text { Capsella bursa-pastoris (Linn.) } \\
\text { Medik. }\end{array}$ & $\begin{array}{l}\text { Clean away heat, } \\
\text { detoxification }\end{array}$ & $\begin{array}{l}\text { Medicinal } \\
\text { diet }\end{array}$ & Stewed with meat & Root & Wild-gathered & ZY-0054 \\
\hline Daji & Compositae & $\begin{array}{l}\text { Cirsium griseum Levl.; Cirsium } \\
\text { lidjiangense Petr. ex Hand.-Mazz.; } \\
\text { Cirsium chlorolepis Petr. ex Hand. } \\
\text {-Mazz.; Cirsium eriophoroides } \\
\text { (Hook.f.) Petrak }\end{array}$ & Tonifying & $\begin{array}{l}\text { Medicinal } \\
\text { diet }\end{array}$ & Stewed with meat & Root & Wild-gathered & $\begin{array}{l}\text { ZLL-0041, ZLL-0042, } \\
\text { ZLL-0043, ZLL-0044 }\end{array}$ \\
\hline Huixiang & Umbelliferae & Foeniculum vulgare Mill. & $\begin{array}{l}\text { Alleviate fatigue,alleviate } \\
\text { backache }\end{array}$ & $\begin{array}{l}\text { Vegetable, } \\
\text { seasoning }\end{array}$ & Steamed with egg & $\begin{array}{l}\text { Tender } \\
\text { stem }\end{array}$ & Cultivated & GYF-0108 \\
\hline Huitiaocai & Chenopodiaceae & Chenopodium album $\mathrm{L}$. & Treat constipation & Vegetable & Made into soup & $\begin{array}{l}\text { Tender } \\
\text { stem }\end{array}$ & Wild-gathered & ZLL-0128 \\
\hline Huangjing & Liliaceae & $\begin{array}{l}\text { Polygonatum cirrhifolium (Wall.) } \\
\text { Royle }\end{array}$ & $\begin{array}{l}\text { Anti-rheumatism, promoting } \\
\text { lactation, }\end{array}$ & $\begin{array}{l}\text { Medicinal } \\
\text { diet }\end{array}$ & Brewed & Root & Wild-gathered & ZLL-0078 \\
\hline Huajiao & Rutaceae & $\begin{array}{l}\text { Zanthoxylum bungeanum } \\
\text { Maxim. }\end{array}$ & $\begin{array}{l}\text { Anti-rheumatism, treat belly } \\
\text { ache }\end{array}$ & Seasoning & Soaked in boiling water & Fruit & Semi-domesticated & ZLL-0056 \\
\hline Heicaowu & Ranunculaceae & $\begin{array}{l}\text { Aconitum stapfianum Hand.- } \\
\text { Mazz. }\end{array}$ & $\begin{array}{l}\text { Anti-rheumatism, treat } \\
\text { stomachache, belly ache }\end{array}$ & $\begin{array}{l}\text { Medicinal } \\
\text { diet }\end{array}$ & Stewed with meat & Root & Wild-gathered & ZLL-0067 \\
\hline Elancai & Cruciferae & Thlaspi arvense L. & Diuresis & Vegetable & Made into soup & $\begin{array}{l}\text { Aerial } \\
\text { part }\end{array}$ & Wild-gathered & ZLL-0029 \\
\hline Dujuanhua & Ericaceae & $\begin{array}{l}\text { Rhododendron yunnanense } \\
\text { Franch; Rhododendron }\end{array}$ & Gut purge & $\begin{array}{l}\text { Snacks, } \\
\text { vegetable }\end{array}$ & Cold dish & Petal & Wild-gathered & ZY-0037, ZY-0038 \\
\hline
\end{tabular}


Table 1 Inventory of medicinal dietary plants used by the Naxi in Lijiang area, Northwest Yunnan, China (Ranked alphabetically, Ethnotaxically organized) (Continued)

\begin{tabular}{|c|c|c|c|c|c|c|c|c|}
\hline & & $\begin{array}{l}\text { hippophaeoides Balf. f. et } \\
\text { W. W. Smith }\end{array}$ & & & & & & \\
\hline Chuanxiong & Umbelliferae & Ligusticum chuanxiong Hort. & Alleviate backache & Vegetable & Steamed with egg & $\begin{array}{l}\text { Tender } \\
\text { stem }\end{array}$ & Cultivated & ZLL-0104 \\
\hline Chonglian & Rosaceae & $\begin{array}{l}\text { Sanguisorba filiformis (Hook. } \\
\text { f.) Hand.-Mazz. }\end{array}$ & Kidney deficiency & $\begin{array}{l}\text { Medicinal } \\
\text { diet }\end{array}$ & Stewed with meat & Root & Wild-gathered & ZLL-0097 \\
\hline Chongcao & Clavicipitaceae & Cordyceps sinensis (Berk.) Sacc. & Treat eye disease & $\begin{array}{l}\text { Medicinal } \\
\text { diet }\end{array}$ & $\begin{array}{l}\text { Stewed with meat, } \\
\text { steamed with egg, } \\
\text { infused with alcohol }\end{array}$ & $\begin{array}{l}\text { Whole } \\
\text { plant }\end{array}$ & Wild-gathered & ZLL-0077 \\
\hline Cheqiancao & Plantaginaceae & Plantago depressa Willd. & Alleviate fatigue,diuresis & Vegetable & Stewed with meat & Root & Wild-gathered & ZLL-0116 \\
\hline Baihe & Liliaceae & $\begin{array}{l}\text { Lilium lankongense Franch.; } \\
\text { Lilium lancifolium Thunb. }\end{array}$ & Moistening lung, Anti-tussive & Vegetable & Stewed with meat & Bulb & Wild-gathered & GYF-0102, GYF-0103 \\
\hline
\end{tabular}


This study was carried out following the code of ethics of the American Anthropological Association [43, 44] and the International Society of Ethnobiology Code of Ethics $[40,45]$. Prior oral informed consent was acquired. Specimen identification was completed with the help of the experts at the Kunming Institute of Botany, and these specimens will be stored in the Herbarium of the Kunming Institute of Botany at the Chinese Academy of Sciences after our further study.

\section{Results}

Ethnobotanical surveys at the study sites found that 41 ethnotaxa of medicinal dietary plants correspond to 55 botanical taxa (species, varieties, or subspecies) belonging to 24 families and 41 genera. At the family level, we found that $60 \%$ of documented plants belonged to seven botanical families, and the most represented families were Asteraceae (16.4\%), Rosaceae (10.9\%), Dioscoreaceae $(7.4 \%)$, Cruciferae (7.4\%), and Liliaceae (7.4 \%) (Fig. 2). These families were similar to other edible plants recorded in the same site, of which Rosaceae (19.8\% species) and Liliaceae (10.3\% species) were the most common. However, the similarity with the medicinal plants of the Naxi is apparently larger, of which Asteraceae (13.1\%) and Labiatae (5.8\%) were the most common family [33]. At the species level, those medicinal dietary plants accounted for $39 \%$ of the total number of edible plant species (146) recorded at the study sites. However, these plants had less overlap with recorded Naxi medicine plants [30]. This indicates that the selection of medicinal dietary plants overlaps with the edible and medicinal plants in the area. However, previous studies may have treated some plants as edible or medicinal only, and the medicinal dietary functions were ignored. Table 1 lists the ethnobotanical information for each plant, including the scientific name, local name, family name, habitat, usage, preparation, and plant part used.

\section{Used parts}

A wide range of plant parts including root, aerial plant, whole plant, fruit, tender stem, kernel, leaf, bulb, pollen, petal, and rhizome or flower from herbaceous (75.6\%) or woody plants $(24.4 \%)$ are used. The root was the most commonly used plant part (34.1\%); the most common seven plant parts are shown in Fig. 3. The remaining less commonly used parts were the bulb, pollen, petal, and rhizome. These results share little similarity to other edible plants, of which the fruit (44.8 $\%)$ and leaf (30.5\%) are the most commonly used parts. However, the used parts were similar to those on the Naxi medicinal plant list, with root as the most commonly used part (43.8\%) [33]. The informants stated that roots contain more substances for good health. Similar thinking is found in TCM, with the use of Panax ginseng as a prominent example.

\section{Preparation}

Mixing plants with other food items was the most common preparation and consumption method. The majority of inventoried medicinal dietary plants were stewed with meat $(34.1 \%)$, followed by use in soup, soaking in boiled water, and steaming with eggs. There were a few other preparations that involved infusion with alcohol, or mixing with honey or brown sugar. The Naxi believe that the meat of an animal has feelings, so it is better to enhance the blood and energy of the human body and prolong life. This concept is also recorded in the Southern Yunnan Materia Medica [46]. Nearly all remedies include only one medicinal dietary plant, and are easy to prepare.

\section{Habitat}

Wild-gathered (68.3\%), semi-domesticated (17.1\%), and cultivated $(14.6 \%)$ were the most common habitats of medicinal dietary plants (Fig. 4). The majority of the medicinal dietary plants of the Naxi were gathered from the

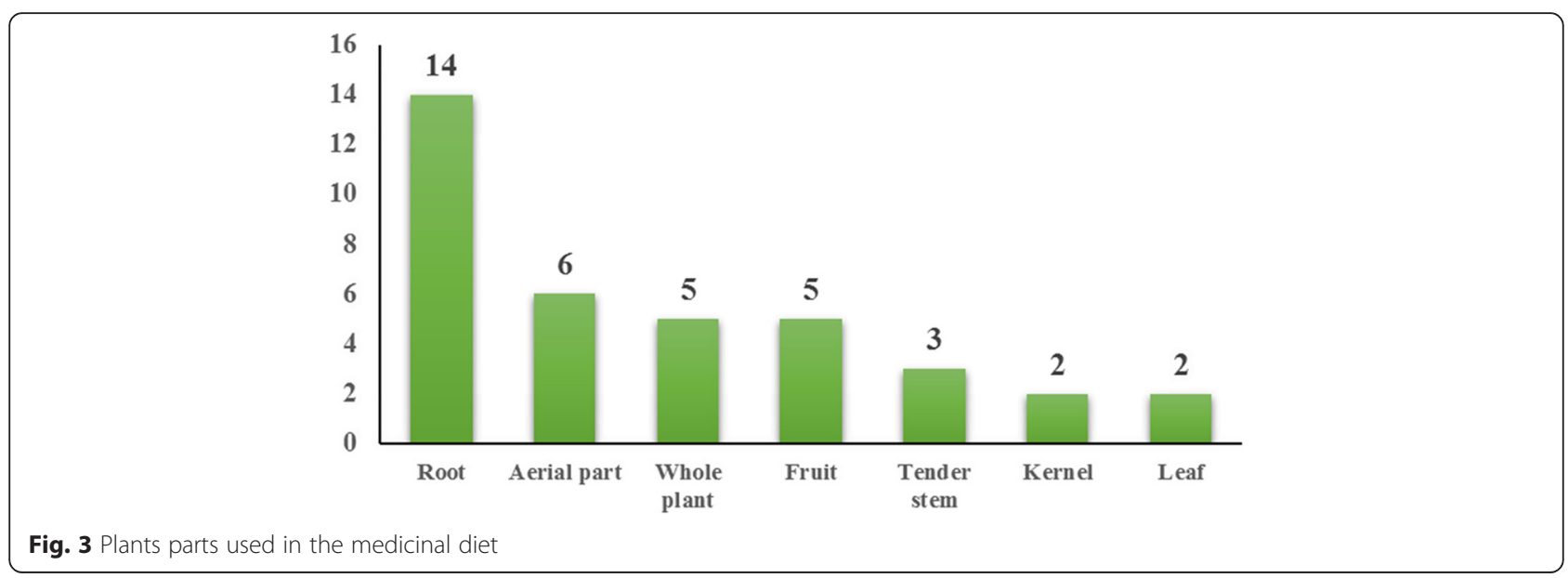




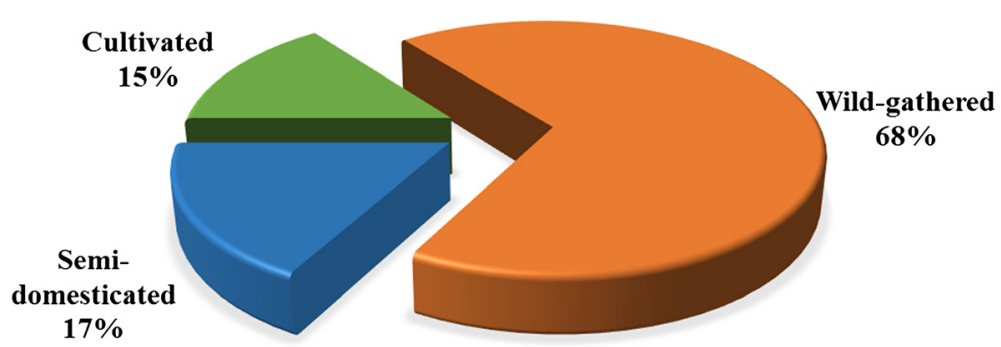

Fig. 4 The habitat of medicinal dietary plants

wild. The Naxi prefer medicinal dietary plants that grow on high mountains, as they believe that these plants are more effective and impart longevity. The Naxi in Wenhai village liked to collect medicinal dietary plants from the Yulong Snow Mountain, and in Shihong village the Naxi collected plants from the Laojun Mountain. The most representative plants were Cordyceps sinensis and Saussurea leucoma. Semi-domesticated plants referred to those plants cultivated in home gardens. The Naxi prefer to grow medicinal plants which collected from the mountains in their home gardens [34], with a part for medicinal dietary use.

\section{Medicinal dietary function}

There are 21 major health conditions that can be treated by the collected medicinal dietary plants. The most common condition that can be treated is alleviating fatigue (42.8\%), followed by tonifying, moistening the lung, and as use as an antitussive (Fig. 5). In addition to the ten types of medical functions shown in Fig. 5, there were ten other functions including treating eye diseases, insomnia, cold, stomachache, abdominal pain, bruises, constipation, postpartum blood stasis, postpartum weakness, calming of the nerves, and promotion of lactation.

\section{Fidelity level}

Sixty-eight percent of medicinal dietary plants used by the Naxi people had a maximum FL value of 100 and 83 $\%$ of the edible dietary plants had a FL value of over 50 . This indicates the general acceptance of inventoried plants as medicinal dietary plants within the Naxi community. Special emphasis was given to some important plants that have maximum FL value. These plants included Polygonatum cirrhifolium, whose tuber is commonly used for promoting lactation, and is a widely used vegetable [47]. Others were Pinus armandii, Cirsium griseum, Cirsium lidjiangense, Cirsium chlorolepis, Cirsium eriophoroides, Ligusticum chuanxiong, Zanthoxylum bungeanum, and

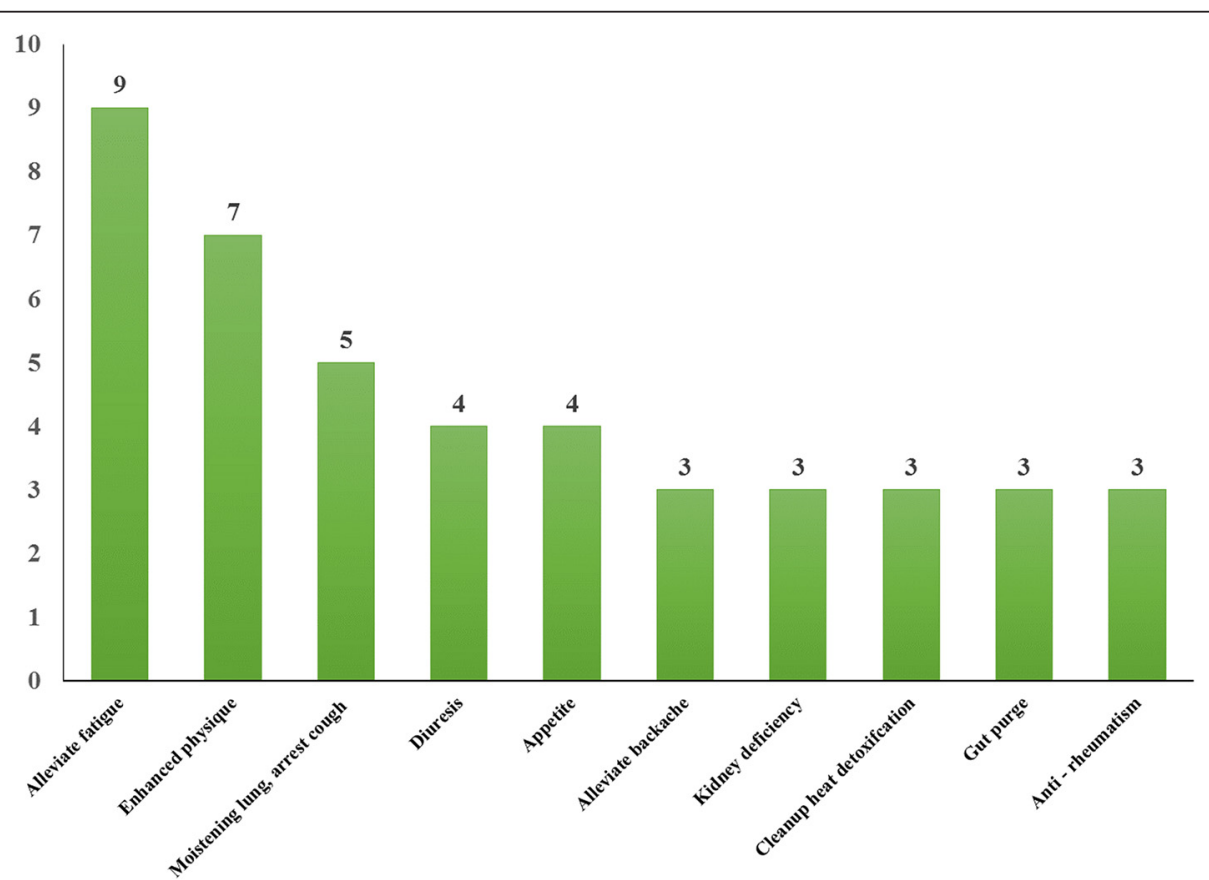

Fig. 5 Medicinal diet function category-number of plants used 
Aconitum stapfianum, which are wildly enjoyed by Naxi people for their good effect. Detailed use and the FL values of medicinal dietary plants are shown in Tables 1 and 2 .

\section{Discussion}

A large number of studies focusing on traditional medical diets have been conducted in China. Of these, two comparable ethnobotanical studies of medicinal dietary plants were conducted by Zhang [48] in Taibai Mountain, and by $\mathrm{Gu}$ [49] concerning Dai people in Xishuangbanna. Zhang's study recorded the use of 183 species of medicinal dietary plants belonging to 61 families and 119 genera. The most represented families were Rosaceae, Liliaceae and Compositae, and the majority were in herb form $(58.5 \%)$. In Zhang's study the whole herb was used $36.6 \%$ of the time, and the main preparation style was cold-dressed and eaten with noodles. The main medicinal functions were relieving fever and eliminating toxins. Gu documented 135 species of medicinal dietary plants, most of which were herbaceous plants, belonging to 49 families and 104 genera. Most plants were used to treat cold, indigestion, diarrhea and injuries. Gu conducted a biochemical investigation into two traditionally important medicinal dietary plants, Gmelina arborea and Strobilanthes cusia. The book Materia Medica of Yunnan records 73 prescription herbs and outlines the character of the Yunnan medicinal diet [46]. The results of our study share many common features with the plants used in Materia Medica of Yunnan, for example, nearly all prescribed medicinal diets include only one medicinal dietary plant, meat is used to enhance the beneficial effects of the plant, and liquor, honey and sugar are used to prepare the plant for consumption.

The richness of plant diversity in any area is evaluated not only by the number of species occurring there, but also by the intensity of associations and the dependence of the indigenous communities on those plants [15]. The medicinal dietary plants of the Naxi people are diverse. Villagers are knowledgeable about the use of various medicinal dietary plants to improve health, and to prevent and treat diseases. Roots are collected and used for the whole year, and green plant items are stored to prolong use through winter. The life of the Naxi people is closely related with medical dietary plants, and their medicinal diets are indispensable to the health of their communities. The changing relationship between humans and the environment has affected the medicinal diets and associated knowledge of the Naxi people. The selection of the medicinal diet overlaps with the edible and medicinal plants in the area. However, most studies have examined edible and medicinal plants separately, while the medicinal dietary functions are ignored.

Although most of the medicinal dietary plants had a maximum fidelity score and were widely used, the safety must be carefully checked. Thirty-nine percent of the
Table 2 Fidelity level of medicinal dietary plants of the Naxi

\begin{tabular}{|c|c|c|}
\hline Local name & Medicinal dietary function & $\mathrm{FL}$ \\
\hline Songhuafeng & Moistening the lung, Antitussive & 100 \\
\hline Chuanxiong & Alleviates backache & 100 \\
\hline Heicaowu & Anti-rheumatism, Treats stomachache, belly pain & 100 \\
\hline Huajiao & Anti-rheumatism, Treats stomachache, belly pain & 100 \\
\hline Huangjing & Anti-rheumatism, Promoting lactation & 100 \\
\hline Chongcao & Treats eye disease & 100 \\
\hline $\mathrm{Ji}$ & Tonifying & 100 \\
\hline Songzi & Moistening the lung, Antitussive & 100 \\
\hline Xuelianhua & Alleviates fatigue, Tonifying & 100 \\
\hline Muer & Gut purge & 100 \\
\hline Wuweizhi & Alleviates fatigue, Treats insomnia & 100 \\
\hline Huixiang & Alleviates fatigue, Alleviates backache & 100 \\
\hline Baihe & Moistening the lung, Antitussive & 100 \\
\hline Shanjingzi & Appetizing, Diuresis & 100 \\
\hline Shanzha & Appetizing, Diuresis & 100 \\
\hline Manjing & Appetizing & 100 \\
\hline Luobo & Appetizing & 100 \\
\hline Xuecha & Treats colds, cleanup heat and detoxification & 100 \\
\hline Mugua & Anti-rheumatism & 100 \\
\hline Qingciguo & Treats postpartum weakness, Tonifying & 100 \\
\hline Yeshanyao & Alleviates fatigue, Tonifying & 100 \\
\hline Niubang & Alleviates fatigue, Tonifying & 100 \\
\hline Xiaohongshen & Alleviates backache, Treat bruises & 100 \\
\hline Xiangyashen & Tonifying kidney & 100 \\
\hline zhuzishen & Treats eye disease & 100 \\
\hline Tiaoshen & Treats insomnia & 100 \\
\hline Jiuhuashen & $\begin{array}{l}\text { Alleviates fatigue, Tonifying, Moistening the lung, } \\
\text { Antitussive }\end{array}$ & 100 \\
\hline Mianshen & Alleviates fatigue, Tonifying & 100 \\
\hline Xiangru & Treats colds & 80 \\
\hline Huitiaocai & Treats constipation & 80 \\
\hline Cheqiancao & Alleviates fatigue, Diuresis & 80 \\
\hline Jiucai & Calms nerves & 60 \\
\hline Songjishen & Treats insomnia & 60 \\
\hline Yekuai & Treats postpartum congestion & 50 \\
\hline Pugongying & Cleanup heat and detoxification & 40 \\
\hline Longdancao & Tonifying kidney & 40 \\
\hline Jicai & Cleanup heat and detoxification & 30 \\
\hline Chonglian & Tonifying kidney & 30 \\
\hline Elancai & Diuresis & 30 \\
\hline Songluo & Moistening the lung, Antitussive & 30 \\
\hline Dujuanhua & Gut purge & 20 \\
\hline
\end{tabular}


medicinal diet plants are not commonly consumed food items (Table 1), although almost all of them are traditional herbs and the medicinal aspects are known. For example, Aconitum in its raw state is a highly toxic plant because of the compound aconitine [50]. There have been many reports of Aconitum poisoning and death in the Yunnan province [51], but it is still widely eaten by the Naxi. As in Qinling Mountain, the preparations of the Aconitum are special [50], and the process is strictly controlled to protect against toxic effects. Scientific evidence on the safety and detoxification of the medicinal dietary plants of the Naxi people must be established before widespread use.

\section{Conclusion}

The medicinal dietary plants used by the Naxi people are diverse. The lives of the Naxi people are closely related with the use of medicinal dietary plants and their associated knowledge of these plants is extensive. These plants are easy to collect and prepare, and are widely used when needed by the Naxi people. The main theory behind the traditional medicinal diet of the Naxi people is to prevent disease by strengthening the body.

A wide spectrum of disorders can be treated by medicinal diets. Most plants have a high fidelity level and are widely used. However, the safety of some medicinal dietary plants is not well understood, and the nutritional elements are unclear. Scientific evidence on the safety, detoxification, and nutrition of medicinal dietary plants of the Naxi people must be established before these medicinal dietary plants can be adopted by modern society to improve health and prevent diseases.

\section{Abbreviations}

FL: Fidelity level; TCM: Traditional Chinese medicine.

\section{Competing interests}

The authors declare that they have no competing interests.

\section{Authors' contributions}

LLZ, YHW and SJP conceived of and designed the study; LLZ, YZ, YFG, and CW conducted field data collection; LLZ did the literature review, interpreted the data, and wrote the manuscript. All authors read and approved the final manuscript.

\section{Acknowledgements}

We are very grateful to the local people in Wenhai, Ludian, and Shihong villages who made this study possible, especially Huanliang He, Guoyan He, and Shen He, who provided invaluable information. We thank Professor Huai Huyin for his assistance. This work was funded by the General Program of National Natural Science Foundation of China (31270379) and National Science and Technology Basic Special of China (2012FY110300).

\section{Author details}

${ }^{1}$ Kunming Institute of Botany, Chinese Academy of Sciences, Kunming 650201, China. ${ }^{2}$ South China Botanical Garden, Chinese Academy of Sciences, Guangzhou 510650, China. ${ }^{3}$ University of Chinese Academy of Sciences, Beijing 100049, China.

Received: 16 May 2014 Accepted: 6 May 2015

Published online: 12 May 2015

\section{References}

1. Wu T-M. Food and western disease: health and nutrition from an evolutionary perspective. J Nutr Educ Behav. 2011;43:207-1.

2. Etkin NL. Edible medicines: an ethnopharmacology of food. Tucson: University of Arizona Press; 2008.

3. Johns T. With bitter herbs they shall eat: chemical ecology and the origins of human diet and medicine. Tucson: The University of Arizona Press; 1990.

4. Leonti M. The co-evolutionary perspective of the food-medicine continuum and wild gathered and cultivated vegetables. Genet Resour Crop Evol. 2012;59:1295-302

5. Leonti M. Herbal teas and the continuum of the food-medicine complex: field methods, contextualisation and cultural consensus. J Ethnopharmacol. 2014;151:1028-30.

6. Pieroni A, Nebel S, Quave C, Münz H, Heinrich M. Ethnopharmacology of liakra: traditional weedy vegetables of the Arbëreshë of the Vulture area in southern Italy. J Ethnopharmacol. 2002;81:165-85.

7. Bonet MÀ, Valles J. Use of non-crop food vascular plants in Montseny biosphere reserve (Catalonia, Iberian Peninsula). Int J Food Sci Nutr. 2002;53:225-48.

8. Moerman D. North American food and drug plants. In: Etkin NL, editor. Eating on the wild side. Tucson: University of Arizona Press; 1994. p. 166-81.

9. Etkin NL. Medicinal cuisines: diet and ethopharmacology. Pharm Biol. 1996;34:313-26.

10. Etkin NL, Ross PJ. Should we set a place for diet in ethnopharmacology? J Ethnopharmacol. 1991;32:25-36

11. Etkin NL, Ross PJ. Food as medicine and medicine as food: an adaptive framework for the interpretation of plant utilization among the Hausa of northern Nigeria. Soc Sci Med. 1982;16:1559-73.

12. Gessler M, Hodel U. In situ conservation of plant genetic resources in home gardens in southern Vietnam. Malaysia: International Plant Genetic Resources Institute; 1997

13. Etkin NL. Plants in indigenous medicine and diet: biobehavioral approaches. East Sussex: Psychology Press; 1986.

14. Fleuret A. Dietary and therapeutic uses of fruit in three Taita communities. In: Etkin NL, editor. Plants in indigenous medicine and diet: biobehavioural approaches. East Sussex: Psychology Press; 1986. p. 151-70.

15. Ogle BM, Tuyet HT, Duyet HN, Dung NNX. Food, feed or medicine: the multiple functions of edible wild plants in Vietnam. Econ Bot. 2003:57:103-17.

16. Weng W, Chen J. The eastern perspective on functional foods based on traditional Chinese medicine. Nutr Rev. 1996;54:S11-6.

17. Chen J. Regularly control of functional food in China. Scand J Nutr. 2000:44:130-1.

18. Unschuld PU. "Huang Di Nei Jing Su Wen": nature, knowledge, imagery in an Ancient Chinese Medical Text. Oakland: University of California Press; 2003.

19. Liu XF. The study of ancient Chinese food therapy therapeutic method. PhD thesis. Beijing: China Academy of Chinese Medical Sciences; 2007.

20. Jing BH, Li ZR. Chinese cultural of food therapy and medicinal diet. Heilongijang Nat Ser. 2001:4:86-93.

21. Tang JL, Liu BY, Ma KW. Traditional Chinese medicine. Lancet. 2008;372:1938-40

22. McNutt K. Medicinals in food: part I: is science coming full circle? Nutr Today. 1995;30:218.

23. Wahlqvist M. Non-nutrients in foods: implications for the food industry. Food Australia. 1992;44:558-60.

24. Lampe JW. Health effects of vegetables and fruit: assessing mechanisms of action in human experimental studies. Am J Clin Nutr. 1999:70:475-90.

25. Craig WJ. Health-promoting properties of common herbs. Am J Clin Nutr. 1999;70:491-9.

26. Balentine DA, Albano MC, Nair MG. Role of medicinal plants, herbs, and spices in protecting human health. Nutr Rev. 1999;57:41-5.

27. Tang NB, Yao HY. Review of the current situation and development prospects of Chinese dietotherapy and herbal medicinal diet. Dietotherapy Herbal Med Diet. 1997;04:45-8.

28. Sun C. Study on the heritage of TCM and the fusion between TCM and Naxi Dongba medicine in Lijiang area. MSc thesis. Yunnan University of Traditional Chinese Medicine; 2013.

29. Li RM, Editorial Committee of Local Records of Lijiang Naxi Autonomous County. Local Records of Lijiang Naxi Autonomous County. Yunnan: Yunnan People Press; 2001

30. Guo DL. Naxi history. Sichuan: Sichuan Nationalities Press; 1994. 
31. Yang FQ. The "Ancient Tea and Horse Caravan Road", the "Silk Road" of Southwest China. Silk Road. 2004;2:29-33.

32. Yang FQ. The Westbound Tea Horse Road. Shanghai: Shanghai People press; 2009.

33. Guo HJ. Medical ethnobotany of Naxi People. MSc thesis. Kunming: Kunming Institute of Botany, Academia Sinica; 1989.

34. Yang L, Ahmed S, Stepp JR. Comparative homegarden medical ethnobotany of Naxi healers and farmers in Northwestern Yunnan. China J Ethnobiol Ethnomed. 2014;10:6.

35. Weckerle CS, Huber FK, Yang YP. Plant knowledge of the Shuhi in the Hengduan Mountains, southwest China. Econ Bot. 2006;60:3-23.

36. Ying TS, Zhang YL. The Endemic Genera of Seed Plants of China. Beijing: Science Press; 1993.

37. Wang XP, Yang ZH, Hong JS. Centers of Plant Diversity. In: Davis SD, Heywood VH, Hamilton AC, editors. Regional Overview: China and East Asia. Volume 2. Oxford: Information Press; 1995.

38. Luo P. Traditional ethnic and biodiversity conservation in the mountain areas of Northwestern Yunnan, China. PhD thesis. Kunming: Kunming Institute of Botany, Chinese Academy of Sciences; 2001.

39. Pei SJ, Huai HY. Ethnobotany. Shanghai: Shanghai Science and Technology Press; 2007.

40. Friedman J, Yaniv Z, Dafni A. A preliminary classification of the healing potential of medicinal plants, based on a rational analysis of an ethnopharmacological field survey among Bedouins in the Negev Desert. Israel J Ethnopharmacol. 1986;16(2):275-87.

41. Alexiades MN. Selected guidelines for ethnobotanical research-a field manual New York, USA: The New York Botanical Garden; 1996.

42. Kim H. Song MJ. Analysis of traditional knowledge about medicinal plants utilized in communities of Jirisan National Park (Korea). J Ethnopharmacol. 2014;153(1):85-9.

43. American Anthropological Association Code of Ethics [http://www.aaanet.org/ issues/policy-advocacy /code-of-ethics.cfm]

44. Kang Y, Luczaj L, Kang J. Wild food plants used by the Tibetans of Gongba Valley (Zhouqu county, Gansu, China). J Ethnobiol Ethnomed. 2014;10:20.

45. International Society of Ethnobiology Code of Ethics (with 2008 additions). [http://ethnobiology.net/code-of-ethics/].

46. Kong QX. Study on the characteristics of medicinal diet of Southern Yunnan Materia Medica. J Yunnan College Traditional Chinese. 1990;13(3):9-11.

47. Wujisguleng W, Liu YL, Long CL. Ethnobotanical review of food uses of Polygonatum (Convallariaceae) in China. Acta Soc Bot Pol. 2012;81(4):239-44.

48. Zhang SJ. Ethnobotanical study on medicine food homology plants of Taibai Mountain region. MSc thesis. Yangling: Northwest Agriculture \& Forestry University; 2013.

49. Gu W. Ethnobotanical investigation on medicinal-edible plants used by the Dai people in Xishuangbanna. PhD thesis. Kunming: Kunming Institute of Botany, Chinese Academy of Sciences; 2013.

50. Kang YX, Luczaj L, Sebastian Y. The highly toxic Aconitum Carmichaelii Debeaux as a root vegetable in the Qinling Mountains (Shaanxi, China) Genet Resour Crop Evol. 2012;59(7):1569-75.

51. 4 famers were killed and 18 people were get poisoned at home by eating aconitum in Lijiang Area [http://society.yunnan.cn/html/2012-02/28/ content_2065356.htm].

\section{Submit your next manuscript to BioMed Central and take full advantage of:}

- Convenient online submission

- Thorough peer review

- No space constraints or color figure charges

- Immediate publication on acceptance

- Inclusion in PubMed, CAS, Scopus and Google Scholar

- Research which is freely available for redistribution 